\title{
A Comparative Study of Refrigerant Side Condensing Heat Transfer Coefficient for Horizontal Mini Channel
}

\author{
Ashok Parekh ${ }^{1}$, Tejendra Patel ${ }^{2}$, Parbhubhai Tailor ${ }^{3}$ \\ ${ }^{1}$ Associate professor, MED, SVNIT Surat, India. \\ ${ }^{2}$ Research Scholar, MED, SVNIT Surat, India. \\ ${ }^{3}$ Professor, MED, SVNIT Surat, India.
}

\begin{abstract}
Heat exchanger developments are driven by increase in energetic efficiency and emission reduction. To reach the required standards, new systems are required based on mini-channels along with macro channels also. Mini-channels can be described as tubes with one or more ports extruded in aluminium or any other material like copper, steel etc. with hydraulic diameter in the range of 0.2 to $3 \mathrm{~mm}$. Its use in refrigeration systems became a reality; thanks to the human ability to make micro-scale systems. Some heat exchanger enterprises have some models developed specially for their use in automotive sector, cooling sector and industrial refrigeration without having knowledge of how these reduced geometries affect the most important parameters such as pressure drop and the heat transfer coefficient. To overcome this, an exhaustive literature review of the last two decades has been performed to determinate the state of the research. Among all the publications, several models have been reviewed to check the predicting capacities of them as most of them were developed for macro channels along with single port mini-channel tubes. This work presents a comparative study of existing heat transfer correlations for horizontal flow through mini-channels. Present work total 317 experimental results of condensation heat transfer coefficient obtained from several published literatures and also various condensation heat transfer correlations are reviewed for horizontal flow through mini-channels. Results of condensation heat transfer coefficient obtained for various correlations are compared with the experimental results. Among all correlations used the Bohdalet's correlation gives value of condensation heat transfer coefficient closer to experimental results and has a mean relative deviation (MRD) of $5.4 \%$ whereas mean absolute relative deviation (MARD) of $20.72 \%$. Hence in present work the effort has been made to find better model to predict the condensation heat transfer coefficient which can fit the experimental data with least MRD and MARD.
\end{abstract}

\section{Introduction}

Nowadays, micro and mini-channels are present in many applications ranging from different heat exchangers in process industry to automotive, electronics and domestic applications. Two-phase flow has been applied to a growing number of fields in recent years because of its higher energy efficiency in comparison with single-phase flow. Compactness is a synonym of charge reduction and this is very important in present day refrigeration systems and heat pumps because of the great contribution of HCFC and HFC refrigerants to the direct greenhouse effect. This reduction is also important for natural refrigerants such as hydrocarbons and ammonia for safety reasons [1]. One of the pioneers authors who studied the influence of reducing diameter in heat transfer coefficient were Kays and London [2]. From then on, the investigation on heat transfer in mini-channels has been one of the most researched topics in this field. Even though many researchers suggested various correlations, they all show a considerable deviation for many new refrigerants. It is partly due to the fact that most of the correlations were based upon a set of data for a few specific fluids and hence certain governing factors valid only for those fluids were mainly emphasized in those correlations. Therefore, it is necessary to develop a correlation based upon a variety of data of many fluids including new alternative refrigerants measured from the same apparatus by a consistent method. Thome et al. [3] correlation presented the lower deviation, less than $30 \%$.Al-Hajri et al. [4] experimentally studied two-phase condensing flows of R134a and R245fa in a single minichannel of $0.7 \mathrm{~mm}$ diameter with high aspect ratio. Pressure drop is accurately predicted by LockhartMartinelli with deviation lower than $20 \%$. Heat transfer coefficient is predicted with errors lower to $20 \%$ by Dobson and Chato correlation with a modified power of the Martinelli parameter. Heo et al. [5] reported a study about in-tube condensation heat transfer characteristics of $\mathrm{CO}_{2}$ in different mini-channels. Multi-port mini channels had hydraulic diameters of $1.5,0.78$ and $0.68 \mathrm{~mm}$ and they were tested from -5 to $5{ }^{\circ} \mathrm{C}$ of saturation temperature. 
Wang et al. [6] presented a short overview of the heat transfer performance of R1234yf versus R134a with previous published data. For in-tube condensation, it was found that the condensation heat transfer coefficients for R1234yf are inferior to those of R134a. Flow pattern influence is very strong in heat transfer processes and momentum. A good revision of recent condensation heat transfer coefficient and pressure drop in tubes of small and large diameter can be found in English and Kandlikar [7].Yang and Webb [8] studied R12 condensation in plain micro-finned multi-port extruded tubes with hydraulic diameters of 2.637 and $1.564 \mathrm{~mm}$. They compared against the correlations developed by Akers et al. [9] and Shah and London [10]. They found that Akers et al. [9] correlation predicted well their experimental data for plain tubes. The authors also showed that high velocity data are over estimated. Yang and Webb et. al. proposed a correlation for heat transfer coefficient prediction in finned mini-channels. This correlation takes into account vapour shear tension and surface tension effects. They proved that at high mass velocities, heat transfer coefficient is controlled by vapour shear tension and the contribution of surface tension is quite small (it is much affected by fin geometry). These authors also proposed a separated asymptotic model for these two effects. They validated the previous model analyzing five different geometries (a single port tube and several multi-port tubes with and without fins) and two refrigerants, R12 and R134a.Webb et al. [11] studied a circular copper tube with a hydraulic diameter of $3.55 \mathrm{~mm}$ and an aluminium multi-port tube of $2.13 \mathrm{~mm}$. They checked their experimental results for R134a with those provided by Shah M.M. et al. [12] and Moser et al. [13] correlations under similar conditions. They found good concordance between their data and both correlation predictions, at 65 ${ }^{\circ} \mathrm{C}$ saturation temperature; they showed that Shah M.M. et al. correlation overestimates their data. The authors attributed this difference to the reduced pressures. In their data, it was $\mathrm{p}_{\text {red }}=0.47$ while Shah M.M. et al. correlation was developed for $0.011<\mathrm{p}_{\mathrm{red}}<0.44$. Accordingly, round single port tubes and multi-port tubes are going to reach the same condensation performance.

\section{Comparative Study of CHTC for Condensation in Annular Flow Regime}

Here, nearly about 209 of experimental data have been taken from literature (Experimental measurements of Aker's et al. , A. Cavallinia at al [14], Dongsoo Jung at al [15] obtained for a $0.952 \mathrm{~mm}$ and $1.304 \mathrm{~mm}$ square channel whereas $1.152 \mathrm{~mm}$ circular minichannel at different saturation temperature) for different refrigerant as working fluid. Comparative assessment of six available different correlations have been done and finding MRD (Mean Relative Deviation) of each correlation. Generally, annular flow correlations are classified into three categories, viz. two-phase multiplier based, shear-based and boundary layer based as given by Dobson et al. [16].The characteristics of the heat transfer mechanism for forced convection condensation can be explained by the Akers etal. [17] correlation, presented in Eq. (1), which was developed for annular flow regime.

$$
N u=0.026 \operatorname{Re}_{L}^{0.8} \operatorname{Pr}_{L}^{0.333}\left(\left(\frac{\mathrm{x}}{1-\mathrm{x}}\right)\left(\frac{\rho_{\mathrm{L}}}{\rho_{\mathrm{V}}}\right)^{0.5}+1\right)^{0.8}
$$

Cavallini et al. [18] proposed a HTC for film condensation inside horizontal tubes.

$N u=0.05 \operatorname{Re}_{L}^{0.8} \operatorname{Pr}_{L}^{0.333}\left(\left(\frac{\mathrm{x}}{1-\mathrm{x}}\right)\left(\frac{\rho_{\mathrm{L}}}{\rho_{\mathrm{V}}}\right)^{0.5}+1\right)^{0.8}$

The Shah et. al. correlation has been compared by researchers commonly for turbulent condensation conditions valid for $\operatorname{Re}_{1} \geq 350$.

$$
N u=0.023 \operatorname{Re}_{L o}^{0.8} \operatorname{Pr}_{L}^{0.4}\left\{1+3.8\left[\frac{x /(1-x)]^{0.76}}{p_{r d}^{0.38}}\right\}(1-x)^{0.8}(3)\right.
$$

Chen et al. [18] developed a generalized correlation for vertical flow using the pressure drop model of Dukler in 1960 and neglecting acceleration head.

$$
N u=0.018\left(\frac{\rho_{L}}{\rho_{V}}\right)^{0.39}\left(\frac{\mu_{v}}{\mu_{L}}\right)^{0.078} \operatorname{Re}_{L}^{0.2}\left(R e_{L o}-R e_{L}\right)^{0.7} \operatorname{Pr}_{L}^{0.65} \text { (4) }
$$

Dobson and Chato et. al. developed a correlation using a two-phase multiplier for an annular flow regime. It is recommended for $\mathrm{G}>500 \mathrm{~kg} / \mathrm{m}^{2} \mathrm{~s}$ for all qualities in horizontal tubes.

$$
\begin{aligned}
& N u=0.023 R e_{L}^{0.8} \operatorname{Pr}_{\mathrm{L}}^{0.3}\left(\frac{2.61}{x_{u}^{0.805}}\right) \\
& N u=0.0274 r_{L} \operatorname{Re}_{L}^{0.0792} x^{0.2268} \emptyset_{v} / x_{n} \\
& \emptyset_{v}^{2}=1.376+8 X_{u}^{1.665} \\
& \mathrm{Nu}=\frac{\mathrm{hd}_{\mathrm{h}}}{\mathrm{k}_{\mathrm{L}}} \\
& \operatorname{Re}_{\mathrm{Lo}}=\frac{\mathrm{Gd}_{\mathrm{h}}}{\mu_{\mathrm{L}}} \\
& \quad \mathrm{X}_{\mathrm{u}}=\left(\frac{\mu_{\mathrm{L}}}{\mu_{\mathrm{v}}}\right)^{0.1}\left[\frac{1-\mathrm{x}}{\mathrm{x}}\right]^{0.9}\left(\frac{\rho_{\mathrm{L}}}{\rho_{\mathrm{V}}}\right)^{0.5} \\
& \mathrm{p}_{\mathrm{rd}}=\frac{\mathrm{p}_{\text {saturted }}}{\mathrm{p}_{\text {critical }}} \\
& \text { Bohdal et. Al }[23] \text { correlation } \\
& N u=25.08 R e_{L}^{0.258} \operatorname{Pr}_{\mathrm{L}}^{-0.495} P_{r d}^{-0.288}\left[\frac{x}{1-x}\right]^{0.266}
\end{aligned}
$$

\section{Comparative Study of CHTC for Film Condensation}

Here, near about 108 of experimental data have been taken from literature (Experimental measurements of Matkovic et al. [19], A. Cavallinia at al [20], Dongsoo Jung at al [21] obtained in a $1 \mathrm{~mm}$ internal hydraulic diameter circular mini channel at $40{ }^{0} \mathrm{C}$ saturation temperature) for R134a refrigerant as working fluid. Comparative assessment of four available different correlations have been done and finding MRD (Mean Relative Deviation) of each correlation. After comparison it has been found that the Bohdal et. al. [22] correlation and haraguchi et al. [23] correlation having minimum MARD (Mean absoluteRelative Deviation) $20.72 \%$ and $20.75 \%$ respectively. It means predicted heat transfer coefficient by using haraguchi's correlation fits the 
experimental data of Matkovic et al., A.Cavallinia et al and Dongsoo Jung et al. The correlations being compared includes the Shah correlation, the Cavallini correlation, the Aker's correlation, the huang's correlation, the
Koyama's correlation and the Haraguchi correlation, as summarized in Table 2 shows mean deviation and accuracy of the nine correlations for the condensation

Table 1. Experimental data sources for condensation heat transfer

\begin{tabular}{|c|c|c|c|c|}
\hline $\begin{array}{c}\text { Data } \\
\text { Sources }\end{array}$ & Refreigerant & $\begin{array}{c}\text { Parameter Range: } \\
\text { Tsat }\left({ }^{\mathbf{0}} \mathbf{C}\right) / \mathbf{G}\left(\mathbf{k g} / \mathbf{m}^{2} \mathbf{s}\right) / \mathbf{x}\end{array}$ & $\begin{array}{c}\text { Geometry Range: } \mathbf{D}_{\mathbf{h}}(\mathbf{m m}) / \mathbf{L}(\mathbf{m m}) \\
\text { /Orientation }\end{array}$ & $\begin{array}{c}\text { Number of } \\
\text { Data points }\end{array}$ \\
\hline $\begin{array}{c}\text { Matkovic et al. [21] } \\
\text { Cavallini a, et al.[18] }\end{array}$ & R134a & $40{ }^{0} \mathrm{C} / 65-1000 / 0.098-0 . .99$ & $\begin{array}{c}1 / 350 / \text { circulalar mini-channel } \\
\text { Horizontal flow }\end{array}$ & 108 \\
\hline $\begin{array}{c}\text { Cavalliniaat al [18] } \\
\text { Dongsoo Jung at al [20] }\end{array}$ & R22/R32/R152A & $40^{0} \mathrm{C} / 150-280 / 0.097-0.70$ & $\begin{array}{c}0.952-1.304 / 380 / \text { square \& circular } \\
\text { mini-channel Horizontal flow }\end{array}$ & 209 \\
\hline
\end{tabular}

Table 2. Comparison between experimental data and correlation prediction

\begin{tabular}{|c|c|c|c|c|c|c|c|c|c|c|}
\hline \multirow[b]{2}{*}{$\begin{array}{c}\text { Data } \\
\text { Sources }\end{array}$} & \multirow[b]{2}{*}{$\begin{array}{c}\text { Errors } \\
\%\end{array}$} & \multicolumn{9}{|c|}{ Corrélations } \\
\hline & & Akers & Cavallini & Shah & Chen & wang & Harahuchi & $\begin{array}{l}\text { Dobson } \\
\text { \&Chato }\end{array}$ & Koyama & Bohdal \\
\hline \multirow{2}{*}{$\begin{array}{l}\text { Cavallinia } \\
\text { at al. [18] }\end{array}$} & MRD & -36.49 & 21.73 & 54.23 & 43.22 & -26.69 & --- & ---- & --- & -12.262 \\
\hline & MARD & 36.49 & 41.035 & 54.23 & $\begin{array}{c}59.05 \\
2\end{array}$ & 30.98 & --- & ---- & --- & 17.875 \\
\hline \multirow{2}{*}{$\begin{array}{c}\text { Dongsoo } \\
\text { Jung at al. } \\
{[20]}\end{array}$} & MRD & -25.47 & 42.93 & $\begin{array}{c}- \\
35.78\end{array}$ & 58.99 & -21.38 & --- & ---- & --- & 23.15 \\
\hline & MARD & 25.47 & 46.92 & 35.78 & 61.38 & 27.70 & --- & ---- & --- & 23.57 \\
\hline \multirow{2}{*}{$\begin{array}{l}\text { Matkovic } \\
\text { et al. [21] } \\
\text { Cavallinia } \\
\text { et al.[18] }\end{array}$} & MRD & 18.65 & -17.56 & $\begin{array}{c}20.03 \\
4\end{array}$ & -- & -- & -10.47 & -24.31 & -19.89 & -- \\
\hline & MARD & 28.65 & 20.56 & 24.34 & --- & -- & 20.75 & 25.14 & 29.85 & --- \\
\hline \multirow[t]{2}{*}{ Average } & MRD & -14.43 & 15.7 & $\begin{array}{c}- \\
23.32 \\
\end{array}$ & 51.10 & -24.03 & -10.47 & -24.31 & -19.89 & 5.4 \\
\hline & MARD & 30.20 & 36.18 & 38.11 & 60 & 29.34 & 20.75 & 25.14 & 29.85 & 20.72 \\
\hline
\end{tabular}

heat transfer coefficient. Researchers have proposed number of their developed correlation to predict the heat transfer of pure substances and mixture boiling and condensing in or on horizontal and vertical tubes, or on vertical plates.

Total 317 experimental data points have been taken from the sources as presented in Table I are used for the comparative study of the six heat transfer correlations as described in section 2 . The results obtained are presented in Table 2, where the MARD is the mean absolute relative deviation and MRD is the mean relative deviation.

Harahauchi's correlation [22]

$$
\begin{array}{r}
h_{\text {pridicted }} \\
R e_{l}^{0.77}
\end{array}=0.0152 \times \frac{k_{l}}{d_{h}} \times\left(1+0.6 P r_{l}^{0.8}\right) \times\left(\frac{\phi_{g}}{\chi_{t t}}\right) \times
$$

Where

$\phi_{g}=1+0.5 \times\left(\frac{G}{\sqrt{g d_{h} \rho_{g}\left(\rho_{l}-\rho_{g}\right)}}\right)^{0.75} \times \chi_{t t}^{0.35}$

Koyama's correlation

$$
\begin{aligned}
h_{\text {pridicted }} & =0.0152 \times \frac{k_{l}}{d_{h}} \times\left(1+0.6 P r_{l}^{0.8}\right) \times\left(\frac{\phi_{g}}{\chi_{t t}}\right) \times \\
R e_{l}^{0.77} & (15)
\end{aligned}
$$

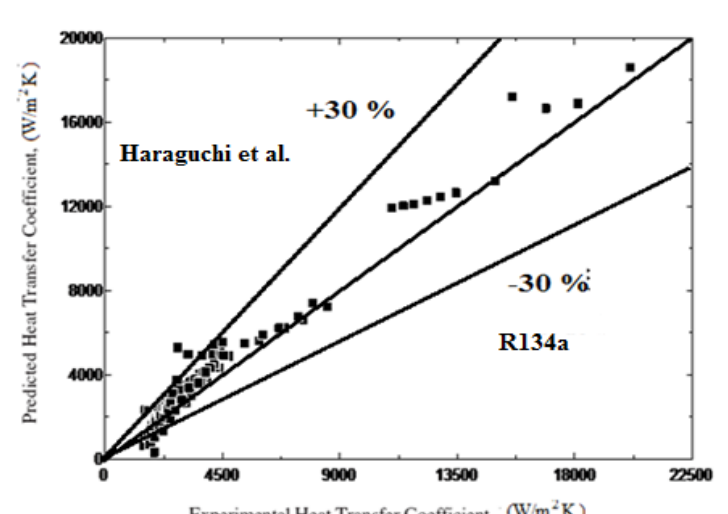

Figure 1. Comparison between experimental and predicted heat transfer coefficient using Haraguchi correlation.

$$
\begin{aligned}
& \text { Where } \\
& \phi_{g}=1+21 \times\left(1-e^{-0.319 d_{h}}\right) \times \chi_{t t}+\chi_{t t}^{2} \\
& M R D=\frac{1}{N} \sum_{i=1}^{N} \frac{h(i)_{c a l}-h(i)_{\text {exp }}}{h(i)_{\text {exp }}} \\
& M A R D=\frac{1}{N} \sum_{i=1}^{N}\left|\frac{h(i)_{\text {cal }}-h(i)_{\text {exp }}}{h(i)_{\text {exp }}}\right|
\end{aligned}
$$

where, $h_{\text {cal }}$ is the calculated value, $h_{\text {exp }}$ is the experimental value, and $\mathrm{N}$ is the number of data points. 


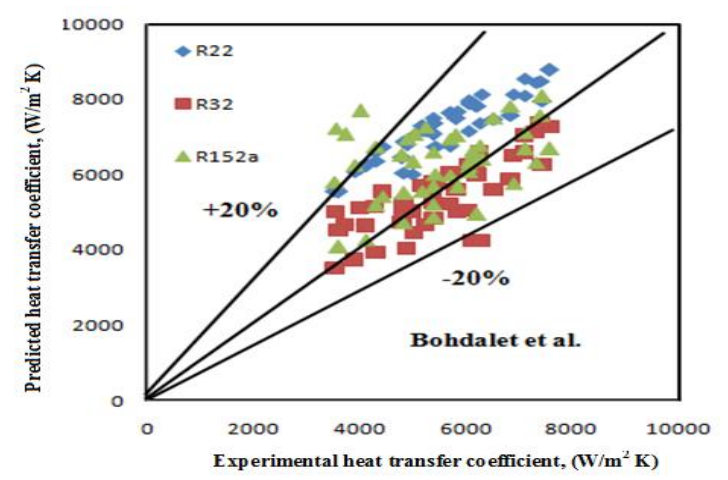

Figure 2. Comparison between experimental and predicted heat transfer coefficient using Bohdal et al. correlation.

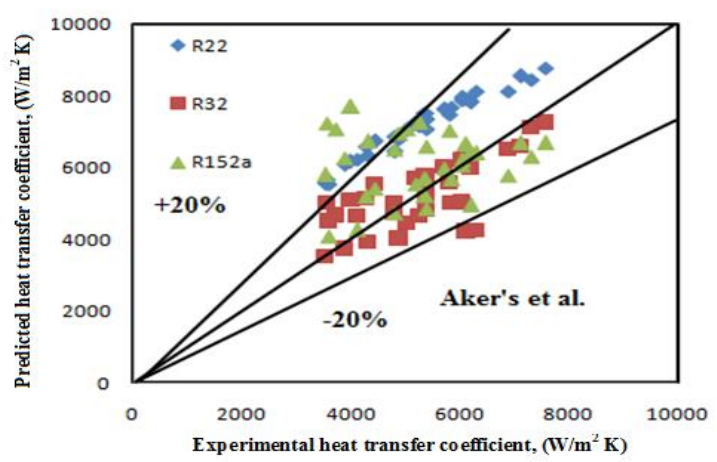

Figure 3. Comparison between experimental and predicted heat transfer coefficient using Akers et al. correlation.

The heat transfer coefficients are compared with the correlation prediction in Fig.1, Fig.2 and Fig. 3. For the annular flow regime based experimental HTC data of R32, R22 \& R152a in square \& circular mini-channel, the Bohdal et al. correlation predicts the data with a MARD $20.72 \%$. The MARD for the Akers et al. correlation is $30.20 \%$. For the film condensation experimental HTC data of R134a in circular mini-channel, the Haraguchis et al. correlation predicts the data with a MARD $20.75 \%$. As per past study of Travis et al. [24] the turbulent liquid film theory and Nusselt's theory which somewhat dictates flow physics behind good agreement; they proposed an empirical asymptotic equation with the power of 2 for predicting the local Nusselt number. These models i.e. Haraguchi, Bohdalet and the Aker's correlation also takes into account free and forced convection. In addition to that both are annular flow regime based model or correlation and as per the literature past flow regime map study of Coleman \& Gerimella [25] the flow pattern is expected to be annular flow or annular film and mist flow for most of the channel length and vapour quality range of $x>0.7$. In the present study also there is all data for annular flow regime and film condensation within this range. Also the thermo physical properties of R134a, R32, and R22 \& R152a do not show the adverse effect on these correlations.

\section{Conclusions}

Total 108 data points of film condensation heat transfer other than annular flow and 209 data point of condensation in annular flow regime are obtained from seven published papers and nine condensation heat transfer correlation are reviewed for flow inside smooth horizontal tubes. After analysis The comparisons show that the Bohdal et al. correlation and the Aker et. al. correlation have the best predictability of experimental data for horizontal flow inside smooth tubes with MRD $5.4 \%$ and MRD $-14.43 \%$ respectively. Also it is seen that Haraguchi et al. correlation showing remarkable agreement with experimental data with MRD $-10.47 \%$.

\section{Nomenclature}

A area, $\mathrm{m}^{2}$

$\mathrm{C}_{\mathrm{P}} \quad$ Specific heat at constant pressure, $\mathrm{kJ} / \mathrm{kgK}$

$\mathrm{C}_{\mathrm{V}} \quad$ Specific heat at constant volume, $\mathrm{kJ} / \mathrm{Kg} \mathrm{K}$

D Smallest hydraulic channel diameter, $\mathrm{mm}$

Fr Froude number

g Gravitational Acceleration, $\mathrm{m} / \mathrm{s}^{2}$

G Mass Velocity, $\mathrm{kg} / \mathrm{m}^{2} \mathrm{~s}$

h Heat transfer coefficient, $\mathrm{W} / \mathrm{m}^{2} \mathrm{~K}$

$\mathrm{h}_{\mathrm{I}} \quad$ Heat transfer coefficient for turbulence region, $\mathrm{W} / \mathrm{m}^{2} \mathrm{~K}$

$\mathrm{h}_{\mathrm{lv}} \quad$ Heat of vaporization, $\mathrm{kJ} / \mathrm{kg}$

I Current, amp

$\mathrm{k}$ Thermal conductivity, W/m K

L Mini channel Length, $\mathrm{m}$

$\mathrm{Nu}$ Nusselt Number

P Pressure, bar

Pr Prandtl Number

$\mathrm{Pr}_{\mathrm{w}}$ Prandtl Number at wall

$P_{\text {red }}$ Reduced pressure

$Q_{\text {in }}$ Heat input, Watt

Q Heat flux, $\mathrm{kW} / \mathrm{m}^{2}$

Re Reynolds number

$\mathrm{T}$ Temperature, ${ }^{\circ} \mathrm{C}$

$\mathrm{T}_{\text {sat }} \quad$ Saturated temperature, ${ }^{\circ} \mathrm{C}$

$\mathrm{T}_{\text {wall }}$ Wall temperature, ${ }^{\circ} \mathrm{C}$

t Thickness, mm

Xtt Martinelli parameter

$\mathrm{X} \quad$ vapour quality

\section{Abbreviations}

CHTC Condensation heat transfer coefficient

CFCs Chlorofluorocarbons

CHE Compact Heat Exchanger

CB coalescing bubble

GWP Global warming potential

HTC Heat Transfer Coefficient

HT Heat transfer

HCFC hydrochlorofluorocarbans

HFC hydrofluorocarbans

MRD Mean relative Deviation

MARD Mean Absolute Relative Deviation

ODP Ozone depletion potential

RMSE Root mean square error

VCR Vapour compression refrigeration

\section{Greek Symbols}




$\begin{array}{ll}f & \text { friction factor } \\ \sigma & \text { surface tension, } \mathrm{N} / \mathrm{m} \\ \tau & \text { shear stress, } \mathrm{N} / \mathrm{m}^{2} \\ \mu & \text { viscosity of condensate film, } \mathrm{N} \mathrm{s} / \mathrm{m}^{2} \\ \rho & \text { density of condensate film, } \mathrm{kg} / \mathrm{m}^{3} \\ \chi \mathrm{tt} & \text { Lockhart-Martinelli parameter } \\ \varphi & \text { vapor two phase pressure drop multiplier } \\ \alpha & \text { void fraction or Volume fraction }\end{array}$

\section{References}

1. F. Poggi, H. Macchi-Tejeda, D. Leducq, and A. Bontemps, Refrigerant charge in refrigerating systems and strategies of charge reduction, International Journal of Refrigeration, 31353-370, (2008).

2. W. M. Kays and A. L. London. Compact Heat Exchangers. McGraw-Hill. New York. Second Edition. (1964).

3. J.R. Thome, S. Nebuloni, "Numerical modeling of laminar annular film condensation for different channel shapes", International Journal of Heat and Mass Transfer 53 (2010) 2615-2627.

4. E. Al-Hajri, A.H. Shooshtari, S. Dessiatoun, and M.M. Ohadi, Performance characterization of R134a and R245fa in a high aspect ratio micro channel condenser, International Journal of Refrigeration, 36 588-600 (2013).

5. J. Heo, H. Park, and R. Yun, Condensation heat transfer and pressure drop characteristics of $\mathrm{CO} 2$ in a micro channel, International Journal of Refrigeration, 36 1657-1668 (2013).

6. C.C. Wang, An overview for the heat transfer performance of HFO-1234yf, Renewable and Sustainable Energy Reviews, 19 444-453 (2013).

7. S.G. Kandlikar, N.J. English, An Experimental Investigation into the Effect of Surfactants on AirWater Two-Phase Flow in Mini channels, Heat Transfer Engineering, 27 99-109 (2006).

8. C.Y. Yang, R.L. Webb, Condensation of R-12 in small hydraulic diameter extruded aluminium tubes with and without micro-fins, International Journal of Heat and Mass Transfer, 39 791-800 (1996).

9. W.W. Akers, H.A. Deans, and O.K. Crosser, Condensing heat transfer within horizontal tubes, Chem. Eng. Progr., 54 (1958).

10. R.K. Shah, Laminar Flow Forced Convection in Ducts, Advances in Heat Transfer, (1978).

11. R.L. Webb, M. Zhang, and R. Narayanamurthy, Condensation heat transfer in small diameter tubes, Heat Transfer, 14 403-408 (1998).

12. Shah, M. M. "A General Correlation for Heat Transfer During film Condensation inside Pipes". Int. J. Heat and Mass Transfer, 22(4), 547-556 (1979).

13. K.W. Moser, B. Na, and R.L. Webb, A New Equivalent Reynolds Number Model for Condensation in Smooth Tubes, Journal of Heat Transfer, 120 410-417 (1998).

14. A. Cavallini a, ${ }^{*}$, G. Censi a, D. Del Col a, L. Dorettia,G.A. Longo b, L. ossetto , "Experimental investigation on condensation heat transfer and pressure drop of new HFC refrigerants (R134a, R125, R32, R410A, R236ea) in a horizontal smooth tube", International Journal of Refrigeration 24 73-87 (2001).

15. Dongsoo Jung*, Kil-hong Song, Youngmok Cho, Sin-jong Kim, "Flow condensation heat transfer coefficients of pure refrigerants", International Journal of Refrigeration 26, 4-11 (2003).

16. Dobson, M. K., \& Chato, J. C. "Condensation in Smooth Horizontal Tubes”. J. Heat Transfer, 120 (1), 193-213 (1998).

17. Akers, W. W., Deans, H. A., \& Crosser, O. K., "Condensing Heat Transfer within Horizontal Tubes", Chemical Engineering Progress Symposium Series, 55,171-176 (1959).

18. Chen, S. L., Gerner, F. M., \& Tien, C.L., "General film Condensation Correlation" Experimental Heat Transfer, 193-107 (1987).

19. Matkovic, A. Cavallini, D. Del Col, L. Rossetto, Experimental study on condensation heat transfer inside a single circular mini channel, Int. J. Heat Mass Transfer 52 (2009) 2311-2323.

20. Cavallini a,, G. Censi a, D. Del Col a, L. Doretti a,G.A. Longo b, L. ossetto , "Experimental investigation on condensation heat transfer and pressure drop of new HFC refrigerants (R134a, R125, R32, R410A, R236ea) in a horizontal smooth tube", International Journal of Refrigeration 24 73-87 (2001).

21. Dongsoo Jung*, Kil-hong Song, Youngmok Cho, Sin-jong Kim, "Flow condensation heat transfer coefficients of pure refrigerants", International Journal of Refrigeration 26 4-11(2003).

22. Bohdal T., Charun H., Sikora M.: Comparative investigations of the condensation of R134a and R404A refrigerants in pipe minichannels. Int. J. Heat Mass Transfer 54(2011), 1963-1974.

23. Haraguchi, H., Koyama, S., Fujii, T., "Condensation of refrigerants HCFC 22, HFC 134a and HCFC 123 in a horizontal smooth tube", (2nd report, proposals of empirical expressions for local heat transfer coefficient). Trans. JSME 60 245-252 (1994).

24. D.P. Traviss, W.M. Rohsenow, and A.B. Baron, Forced Convection Condensation in tubes: A heat Transfer Correlation for condenser design, ASHRAE Transactions, 79 157-165(1973).Coleman J.

25. W., Garimella S., "Two phase flow regime transition in microchannel tube: the effect of hydraulic diameter, orlando, ASME, Heat transfer devision, 71-83 (2000). 